\title{
The Quinonoid Zwitterion Interlayer for the Improvement of Charge Carrier Mobility in Organic Field-Effect Transistors
}

\author{
Adam Luczak ${ }^{1}$, Angélina Torres Ruiz ${ }^{2}$, Simon Pascal ${ }^{2} \oplus$, Adrian Adamski ${ }^{1,3}$, Jarosław Jung ${ }^{1}$, \\ Beata Luszczynska ${ }^{1, *}$ and Olivier Siri ${ }^{2, * \mathbb{D}}$ \\ 1 Department of Molecular Physics, Faculty of Chemistry, Lodz University of Technology, Zeromskiego 116, \\ 90-924 Lodz, Poland; adam.luczak@p.lodz.pl (A.L.); adrian.adamski@pwr.edu.pl (A.A.); \\ jaroslaw.jung@p.lodz.pl (J.J.) \\ 2 CNRS, CINaM, UMR 7325, Campus de Luminy, Aix Marseille Université, CEDEX 09, 13288 Marseille, France; \\ angelina.torres-ruiz@etu.univ-amu.fr (A.T.R.); pascal@cinam.univ-mrs.fr (S.P.) \\ 3 Department of Experimental Physics, Faculty of Fundamental Problems of Technology, Wroclaw University \\ of Science and Technology, Wyb. Wyspianskiego 27, 50-370 Wroclaw, Poland \\ * Correspondence: beata.luszczynska@p.lodz.pl (B.L.); olivier.siri@univ-amu.fr (O.S.)
}

\section{check for} updates

Citation: Luczak, A.; Ruiz, A.T.; Pascal, S.; Adamski, A.; Jung, J.; Luszczynska, B.; Siri, O. The Quinonoid Zwitterion Interlayer for the Improvement of Charge Carrier Mobility in Organic Field-Effect Transistors. Polymers 2021, 13, 1567 https://doi.org/10.3390/ polym13101567

Academic Editor: Ana Maria de Matos Charas

Received: 20 April 2021

Accepted: 10 May 2021

Published: 13 May 2021

Publisher's Note: MDPI stays neutral with regard to jurisdictional claims in published maps and institutional affiliations.

Copyright: (C) 2021 by the authors. Licensee MDPI, Basel, Switzerland. This article is an open access article distributed under the terms and conditions of the Creative Commons Attribution (CC BY) license (https:// creativecommons.org/licenses/by/ $4.0 /)$.

\begin{abstract}
The interface between the semiconductor and the dielectric layer plays a crucial role in organic field-effect transistors (OFETs) because it is at the interface that charge carriers are accumulated and transported. In this study, four zwitterionic benzoquinonemonoimine dyes featuring alkyl and aryl $N$-substituents were used to cover the dielectric layers in OFET structures. The best interlayer material, containing aliphatic side groups, increased charge carrier mobility in the measured systems. This improvement can be explained by the reduction in the number of the charge carrier trapping sites at the dielectric active layer interface from $10^{14} \mathrm{eV}^{-1} \mathrm{~cm}^{-2}$ to $2 \times 10^{13} \mathrm{eV}^{-1} \mathrm{~cm}^{-2}$. The density of the traps was one order of magnitude lower compared to the unmodified transistors. This resulted in an increase in charge carrier mobility in the tested poly [2,5-(2-octyldodecyl)-3,6diketopyrrolopyrrole-alt-5,5-(2,5-di(thien-2-yl)thieno [3,2-b]thiophene)] (DPPDTT)-based transistors to $5.4 \times 10^{-1} \mathrm{~cm}^{2} \mathrm{~V}^{-1} \mathrm{~s}^{-1}$.
\end{abstract}

Keywords: zwitterionic benzoquinonemonoimine; organic field-effect transistors; interface; charge carrier trapping; electrostatic force microscopy

\section{Introduction}

The interface between semiconductors and dielectrics has attracted much attention due to its effects on the morphology of organic semiconductors (OSCs) and charge transport in organic field-effect transistors (OFETs) [1]. Several interfacial factors have been identified as influencing the performance of OFETs [2]. Important parameters for the semiconductor-insulator interface include insulator surface roughness, surface energy, surface polarity, and the dielectric constant [3]. These parameters can combine to produce several effects, such as changes to the morphological structure of the semiconductor thin film and improved charge transport performance, with strong dependence on the hydrophobicity of the substrate surface. OSC s can be deposited on the dielectric surface by different technological techniques such as vacuum evaporation or coating from solution. The properties of the deposited layer strictly depend on the molecular stacking of OSC molecules. The most favorable stacking of OSC involves face-to-face $\pi-\pi$ interactions [4], which generate the shortest intermolecular distances and very good $\pi$-electron delocalization. This enables improved charge carrier transport between molecules by hopping [5]. Such arrangements are obtained when the dielectric surface has hydrophobic properties. The presence of alkyl chains borne by OSC molecules implies arrangements in which the long axes of the OSC molecules are parallel to the substrate surface. Due to its hydrophobic nature, an OSC-modified dielectric interface may inhibit protonation of the siloxyl groups 
on the $\mathrm{SiO}_{2}$ dielectric surface, resulting in better performance and improved stability of the channel in the OFET [6]. However, most metal oxide dielectric surfaces (e.g., $\mathrm{SiO}_{2}$ ) are hydrophilic [6], and for that reason the surface of the dielectric has to be tailored to match the hydrophobicity of the OSC.

Most materials used for surface modification in OFET fabrication are based on organosilicon derivatives such as hexamethyldisilazane (HMDS) or octadecyltrimethoxysilane (OTS) [7]. These materials are able to increase the hydrophobicity at the OSC-metal oxide interface. For example, the water contact angle can be increased to $110^{\circ}$ at a surface modified with HMDS [6]. However, the protocol for such modification requires the use of high temperatures, oxygen plasma treatment, or piranha acid (i.e., an aqueous $\mathrm{H}_{2} \mathrm{SO}_{4} / \mathrm{H}_{2} \mathrm{O}_{2}$ solution). In this context, the quality of the semiconductor-gate dielectric interface is critical for the performance of OFETs [8-10]. Each disorder of the electric field strength on the above gate dielectric can create charge traps or additional charge carriers, depending on the character of the irregularity [10]. The performance of OFETs is strongly influenced by the polarity of the dielectric surfaces. The presence of higher polar surfaces may cause lower charge carrier mobility, and hysteresis is seen in the I-V characteristics [9]. The presence of defects at the interface is visible in the current-voltage curves as any of the following: (i) hysteresis, which is the difference between the curves measured with increased and decreased drain voltage [11]; (ii) a high OFF current value; or (iii) an ON current smaller than those described in the literature [12].

To prevent hysteresis and provide good charge transport properties in thin OSC films, the electric field at the interface has to be monotonically variable along the transistor channel. Thus, the deposition of a semiconductor-dielectric interlayer is necessary to improve the quality of the transistor. As already mentioned, the most popular form of dielectric surface modification consists of the deposition of an ultrathin layer of an organosilicon compound such as HMDS or OTS $[5,13,14]$. Previous studies show that the existence of poor interface contacts and energy losses in devices can be overcome by the use of zwitterions as an interlayer to improve performance [15-19]. The remarkable properties of zwitterions can be explained by their large intrinsic dipole moment. They are also soluble in orthogonal solvents, which means that a previously deposited zwitterionbased layer will not be dissolved during the deposition of a semiconducting layer using spin-coating methods.

Here, we propose an innovative approach, whereby an ultrathin layer of organic dipolar molecules endowed with a large intrinsic dipole (ca. $10 \mathrm{D})$ is deposited between the silicon wafer and the OSC layer. We decided to investigate zwitterionic benzoquinonemonoimine (BQMI) dyes 1-4 (Scheme 1), which have recently been proposed for the creation of molecular films following adsorption [20-24], the polymerization of metallic surfaces [25-27], for use in interfaces [28,29], and, more recently, as interlayers in graphene transistors [30]. Lin et al. reported a zwitterion-based cathode interlayer in organic photovoltaics, showing that the introduction of such interlayer significantly suppresses trap-assisted recombination in photovoltaics. Moreover, the efficiency of the device was fairly insensitive to the interlayer thickness, which could be beneficial for massproduction technologies such as ink-jet printing or screen printing [31]. The variation of the chemical functions of these BQMI dyes (i.e., the modification of the N-substituents) by the transamination reaction [32] provides an opportunity to tune the degree of hydrophobicity and to create a smooth and homogeneous charge on the dielectric surface. However, there are no reports in the literature on their use as interlayer components to improve the quality of the semiconductor-dielectric interface in OFETs. 

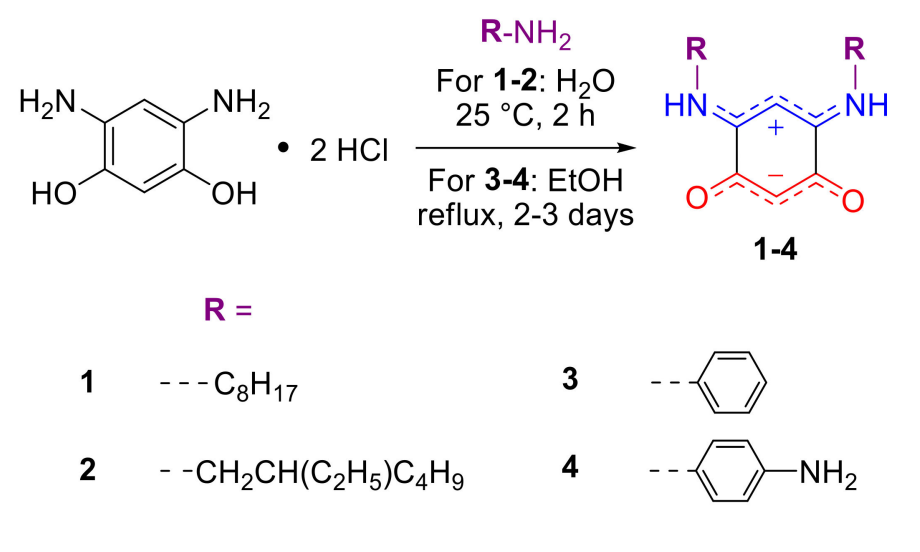

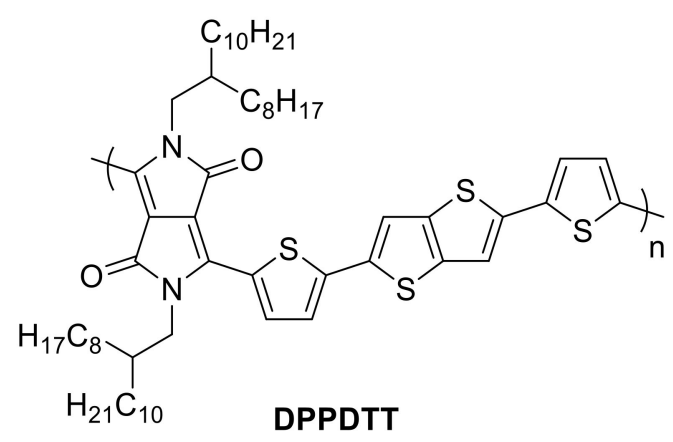

Scheme 1. A series of zwitterionic BQMIs (1-4) used as modifiers of the dielectric surface, and the schematic structure of the DPPDTT organic semiconductor.

\section{Materials and Methods}

\subsection{Materials and Synthesis}

The organic semiconductor poly [2,5-(2-octyldodecyl)-3,6-diketopyrrolopyrrole-alt5,5-(2,5-di(thien-2-yl)thieno [3,2-b]thiophene)] (abbreviated as DPPDTT), characterized by a molecular weight (MW) of $290.668 \mathrm{kDa}$ and a polydispersity index (PDI) of 2.03, was purchased from ABCompany $\mathrm{GmbH}$ (Riedering, Germany). Silicon wafers were procured from the same source. Solvents (HPLC grade) were provided by Sigma-Aldrich (Merck KGaA, Darmstadt, Germany). All compounds and solvents were used as received, without additional treatment, except for compounds 3-4, which were prepared according to procedures described elsewhere [33,34]. The synthesis of all compounds (1-4) is described below, starting from 4,6-diaminoresorcinol dihydrochloride (Sigma-Aldrich) or unsubstituted BQMI zwitterions. Melting points (M.P.) were measured in open capillary tubes using a STUART SMP30 melting points apparatus and are presented without correction.

\subsection{Synthesis of Compound $\mathbf{1}$}

4,6-Diaminoresorcinol dihydrochloride ( $500 \mathrm{mg}, 1.76 \mathrm{mmol}, 1$ equiv.) was dissolved in $10 \mathrm{~mL}$ of distilled water. Next, $n$-octylamine $(2.33 \mathrm{~mL}, 14.08 \mathrm{mmol}, 10$ equiv.) was added and the solution was stirred in the presence of air at room temperature for $2 \mathrm{~h}$. The mixture was extracted with dichloromethane and the organic layer was washed twice with distilled water, dried over anhydrous $\mathrm{Na}_{2} \mathrm{SO}_{4}$, filtered, and evaporated under reduced pressure. The residue was then triturated in pentane, filtered on sintered glass, and finally dried under a vacuum to afford product 1 as a pink solid (358 $\mathrm{mg}, 73 \%$ yield). M.P.: $129^{\circ} \mathrm{C} .{ }^{1} \mathrm{H}$ NMR $\left(\mathrm{CDCl}_{3}, 400 \mathrm{MHz}\right): \delta=8.24(\mathrm{br} \mathrm{s}, 2 \mathrm{H}, \mathrm{NH}), 5.45(\mathrm{~s}, 1 \mathrm{H}, \mathrm{CH}), 5.12(\mathrm{~s}, 1 \mathrm{H}$, $\mathrm{CH}), 3.35\left(\mathrm{~m}, 4 \mathrm{H}, \mathrm{NCH}_{2}\right), 1.73$ (quint, $\left.{ }^{3} \mathrm{~J}=7.6 \mathrm{~Hz}, 4 \mathrm{H}, \mathrm{CH}_{2}\right), 1.31-1.27\left(\mathrm{~m}, 20 \mathrm{H}, \mathrm{CH}_{2}\right)$, $0.88\left(\mathrm{t},{ }^{3} \mathrm{~J}=7.0 \mathrm{~Hz}, 6 \mathrm{H}, \mathrm{CH}_{3}\right) .{ }^{13} \mathrm{C}\left\{{ }^{1} \mathrm{H}\right\} \mathrm{NMR}\left(\mathrm{CDCl}_{3}, 100 \mathrm{MHz}\right): \delta=172.5(\mathrm{C}), 156.7(\mathrm{C})$, 99.0 (CH), $80.7(\mathrm{CH}), 43.4\left(\mathrm{NCH}_{2}\right), 31.9\left(\mathrm{CH}_{2}\right), 29.2\left(\mathrm{CH}_{2}\right), 29.2\left(\mathrm{CH}_{2}\right), 28.4\left(\mathrm{CH}_{2}\right), 27.1\left(\mathrm{CH}_{2}\right)$, $22.7\left(\mathrm{CH}_{2}\right), 14.2\left(\mathrm{CH}_{3}\right)$. IR (neat, $\left.\mathrm{cm}^{-1}\right): v=3166,2953,2920,2853,1642,1528,1472,1368$, 
$1290,1263,1179,949,857,822,780,724$. HRMS (ESI+): $m / z$ calculated for $[\mathrm{M}+\mathrm{H}]^{+}: 363.3006$ $\left(\mathrm{C}_{22} \mathrm{H}_{39} \mathrm{~N}_{2} \mathrm{O}_{2}{ }^{+}\right)$, found: 363.3002 .

\subsection{Synthesis of Compound $\mathbf{2}$}

4,6-Diaminoresorcinol dihydrochloride (500 mg, $2.35 \mathrm{mmol}, 1$ equiv.) and 2-ethylhexylamine $(2.32 \mathrm{~mL}, 23.47 \mathrm{mmol}, 10$ equiv.) were dissolved in water $(10 \mathrm{~mL})$. The reaction was stirred for $2 \mathrm{~h}$ at room temperature. The crude mixture was diluted with dichloromethane, washed with water, and then dried over anhydrous $\mathrm{Na} 2 \mathrm{SO} 4$ and concentrated. The resulting solid was purified via dissolution in a minimum amount of dichloromethane, followed by precipitation in pentane and filtration on sintered glass. The powder was rinsed several times with pentane and finally dried under a vacuum to afford product 2 as a purple solid (534 mg, $63 \%$ yield). M.P.: $171{ }^{\circ} \mathrm{C} .{ }^{1} \mathrm{H}$ NMR $\left(400 \mathrm{MHz} \mathrm{CDCl}_{3}\right): \delta=8.28(\mathrm{~s}, 2 \mathrm{H}, \mathrm{NH})$, $5.46(\mathrm{~s}, 1 \mathrm{H}, \mathrm{CH}), 5.14(\mathrm{~s}, 1 \mathrm{H}, \mathrm{CH}), 3.27\left(\mathrm{t}^{3}{ }^{3} \mathrm{~J}=6.1 \mathrm{~Hz}, 4 \mathrm{H}, \mathrm{NCH}_{2}\right) 1.68(\mathrm{~m}, 2 \mathrm{H}, \mathrm{CH}) 1.44-1.31$ $\left(\mathrm{m}, 16 \mathrm{H}, \mathrm{CH}_{2}\right), 0.95-0.89\left(\mathrm{~m}, 12 \mathrm{H}, \mathrm{CH}_{3}\right) .{ }^{13} \mathrm{C}\left\{{ }^{1} \mathrm{H}\right\} \mathrm{NMR}(\mathrm{CDCl} 3,100 \mathrm{MHz}): \delta=172.4(\mathrm{C})$, $157.0(\mathrm{C}), 98.8(\mathrm{CH}), 80.7(\mathrm{CH}), 46.5(\mathrm{NCH} 2), 39.1(\mathrm{CH}), 31.2\left(\mathrm{CH}_{2}\right), 29.0\left(\mathrm{CH}_{2}\right), 24.5\left(\mathrm{CH}_{2}\right)$, $23.0\left(\mathrm{CH}_{2}\right), 14.2\left(\mathrm{CH}_{3}\right), 11.0\left(\mathrm{CH}_{3}\right)$. IR (neat, $\left.\mathrm{cm}^{-1}\right): v=3168,2956,2924,2860,1642,1530$, 1478, 1451, 1377, 1352, 1301, 1233, 1126, 1060, 954, 851, 822, 781, 732. HRMS (ESI+): $\mathrm{m} / \mathrm{z}$ calculated for $[\mathrm{M}+\mathrm{H}]^{+}: 363.3006\left(\mathrm{C}_{22} \mathrm{H}_{39} \mathrm{~N}_{2} \mathrm{O}_{2}{ }^{+}\right)$, found: 363.3005 .

\subsection{Synthesis of Compound 3}

Unsubstituted BQMI (250 mg, $1.81 \mathrm{mmol}, 1$ equiv.) and aniline $(8.43 \mathrm{~g}, 90.5 \mathrm{mmol}$, 50 equiv.) were dissolved in absolute ethanol $(25 \mathrm{~mL})$. The reaction mixture was heated to reflux for 3 days and the solvent was evaporated under reduced pressure. $\mathrm{Et}_{2} \mathrm{O}$ was added to the reaction mixture. The precipitate was filtered on sintered glass then rinsed with $\mathrm{Et}_{2} \mathrm{O}$. The filtrate was put aside, and the remaining precipitate was rinsed with acetone, $\mathrm{DCM}$, and $\mathrm{MeOH}$. The resulting filtrate was evaporated to afford product 3 as a brown solid (128 mg, 24\% yield). M.P: $260{ }^{\circ} \mathrm{C} .{ }^{1} \mathrm{H}$ NMR (400 MHz, DMSO-d6): $\delta=10.97$ (br s, $2 \mathrm{H}, \mathrm{NH}), 7.39\left(\mathrm{~m}, 8 \mathrm{H}, \mathrm{CH}_{\mathrm{Ar}}\right), 7.29\left(\mathrm{t},{ }^{3} \mathrm{~J}=7.1 \mathrm{~Hz}, 2 \mathrm{H}, \mathrm{CH}_{\mathrm{Ar}}\right), 5.81(\mathrm{~s}, 1 \mathrm{H}, \mathrm{CH}), 5.20(\mathrm{~s}, 1 \mathrm{H}$, $\mathrm{CH}) \cdot{ }^{13} \mathrm{C}\left\{{ }^{1} \mathrm{H}\right\}$ NMR (101 MHz, DMSO-d6): $\delta=171.9$ ( $\left.\mathrm{C}_{\text {quat }}\right), 155.5$ ( $\left.\mathrm{C}_{\text {quat }}\right), 136.5$ (C $\left.\mathrm{C}_{\text {quat }}\right)$, $129.2(\mathrm{CH}), 127.5(\mathrm{CH}), 124.9(\mathrm{CH}), 98.2(\mathrm{CH}), 85.2(\mathrm{CH})$. IR (neat, $\left.\mathrm{cm}^{-1}\right): v=3286,3043$, 2119, 2088, 2007, 1957, 1722, 1637, 1576, 1473, 1437, 1392, 1356, 1286, 1232, 1176, 1107, 1022, 972, 921, 854, 796, 750, 692. HRMS (ESI+): $\mathrm{m} / z$ calculated for $\left[\mathrm{M}+\mathrm{H}^{+}\right]: 291.1128$ $\left(\mathrm{C}_{18} \mathrm{H}_{14} \mathrm{~N}_{2} \mathrm{O}_{2}{ }^{+}\right)$, found: 291.1129.

\subsection{Synthesis of Compound 4}

Under an inert atmosphere, 1,4-phenylenediamine dihydrochloride $(11.86 \mathrm{~g}, 65.16 \mathrm{mmol}$, 30 equiv.) and DIPEA ( $22.55 \mathrm{~mL}, 130.32 \mathrm{mmol}, 60$ equiv.) were added to a suspension of unsubstituted BQMI (300 mg, $2.17 \mathrm{mmol}$, 1 equiv.) in absolute ethanol $(50 \mathrm{~mL})$. The reaction mixture was heated to reflux for 4 days. The formed precipitate was filtered on a sintered glass. The crude solid was washed with ethyl acetate, DCM, acetone, and $\mathrm{Et}_{2} \mathrm{O}$ to afford product 4 as a black solid (194 mg, $28 \%$ yield). M.P: $>300{ }^{\circ} \mathrm{C}$ (decomposition). ${ }^{1} \mathrm{H}$ NMR $(400 \mathrm{MHz}, \mathrm{DMSO}-\mathrm{d} 6): \delta=10.42(\mathrm{br} \mathrm{s}, 2 \mathrm{H}, \mathrm{NH}), 7.04\left(\mathrm{~d},{ }^{3} \mathrm{~J}=7.7 \mathrm{~Hz}, 4 \mathrm{H}, \mathrm{CH}_{\mathrm{Ar}}\right), 6.54(\mathrm{~d}$, $\left.{ }^{3} J=7.7 \mathrm{~Hz}, 4 \mathrm{H}, \mathrm{CH}_{\mathrm{Ar}}\right), 5.87(\mathrm{~s}, 1 \mathrm{H}, \mathrm{CH}), 5.42\left(\mathrm{br} \mathrm{s}, 4 \mathrm{H}, \mathrm{NH}_{2}\right), 5.11(\mathrm{~s}, 1 \mathrm{H}, \mathrm{CH}) .{ }^{13} \mathrm{C}\left\{{ }^{1} \mathrm{H}\right\}$ NMR (101 MHz, DMSO-d6): $\delta=172.4\left(\mathrm{C}_{\text {quat }}\right), 153.3\left(\mathrm{C}_{\text {quat }}\right), 148.2\left(\mathrm{C}_{\text {quat }}\right), 125.3(\mathrm{CH})$, 124.6 ( $\mathrm{C}_{\text {quat }}$ ), $113.7(\mathrm{CH}), 98.1(\mathrm{CH}), 84.9(\mathrm{CH})$. IR (neat, $\left.\mathrm{cm}^{-1}\right): v=3448,3417,3167,1629$, 1604, 1540, 1507, 1473, 1437, 1348, 1282, 1239, 1201, 1167, 1131, 945, 906, 867, 821, 756, 710. HRMS (ESI+): $m / z$ calculated for $\left[\mathrm{M}+\mathrm{H}^{+}\right]$: $321.1346\left(\mathrm{C}_{18} \mathrm{H}_{17} \mathrm{~N}_{4} \mathrm{O}_{2}{ }^{+}\right)$, found: 321.1344.

\subsection{OFET Preparation}

The semiconducting material DPPDTT was dissolved in toluene to prepare a solution with a concentration of $10 \mathrm{mg}$ per $1 \mathrm{~mL}$. The BQMI molecules were dissolved in $\mathrm{N}, \mathrm{N}$-dimethylformamide (DMF) to obtain solutions with a concentration of $8 \mathrm{mmol} \mathrm{L}-1$. Silicone substrates with a $300 \mathrm{~nm} \mathrm{SiO}$ layer were cleaned in an ultrasonic bath (Bandelin electronic, Berlin, Germany)of isopropanol and acetone for $15 \mathrm{~min}$. Next, the spin- 
coating method was used to produce BQMI layers (Spin-coater, 3D Nano, Kraków, Poland). The BQMI in DMF solutions were deposited onto the substrates and rotated with a velocity of 8000 RPM for $2 \mathrm{~min}$. After cleansing and BQMI deposition, the substrates were transferred to a glove-box system with an inner nitrogen atmosphere. All semiconducting films were fabricated using the spin-coating technique: $200 \mu \mathrm{L}$ of the solution was dispensed on the substrate, followed by spinning with a rotational velocity of 2000 RPM for $2 \mathrm{~min}$. The film obtained as a result of the process had a thickness $60 \mathrm{~nm}$. The prepared films were annealed at $90^{\circ} \mathrm{C}$ for $1 \mathrm{~h}$ under a vacuum to remove the solvent residues. The gold source and drain electrodes were thermally evaporated through a shadow mask to a thickness of $60 \mathrm{~nm}$ (shown using a quartz crystal microbalance). As a result, OFETs were constructed in the bottom gate, with a top contact configuration (Figure 1). In all cases, the dimensions of the transistor channels were: width (W) $1 \mathrm{~mm}$ and length (L) $30 \mu \mathrm{m}$.

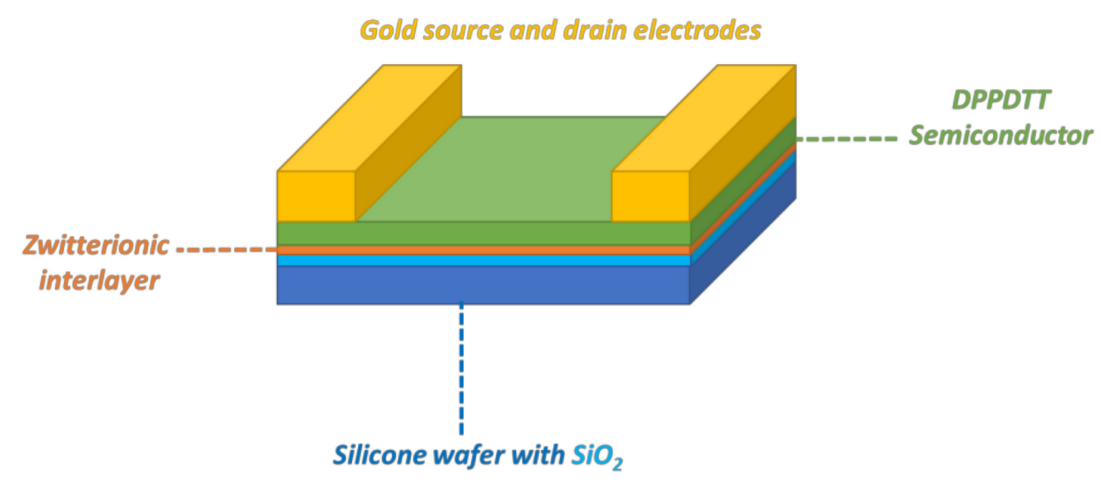

Figure 1. Scheme of an OFET with an $\mathrm{Si}$ gate electrode, $\mathrm{SiO}_{2}$ insulating layer, $\mathrm{BQMI}$ zwitterionic layer, DPPDTT semiconducting film, Au source, and drain electrodes.

\subsection{Measurements and Instruments}

Nuclear magnetic resonance (NMR) spectra were recorded on a JEOL ECS400 NMR spectrometer (JEOL Ltd., Akishima, Japan) at room temperature. The NMR chemical shifts are given in ppm ( $\delta$ ) relative to Me4Si with solvent resonances used as internal standards $\left(\mathrm{CDCl}_{3}\right.$ : $7.26 \mathrm{ppm}$ for ${ }^{1} \mathrm{H}$ and 77.2 for $\left.{ }^{13} \mathrm{C}\right)$. Infra-red (IR) spectra were recorded on an Agilent Cary 630 FTIR (Agilent, Santa Clara, CA, USA) equipped with attenuated total reflectance (ATR) sampling. High-resolution mass spectrometry (HRMS) analyses were performed by the Spectropole center of chemical analysis at Aix-Marseille University using a QStar Elite (Applied Biosystems SCIEX, Toronto, ON, Canada) or SYNAPT G2 HDMS (Waters, Wilmslow, UK) spectrometer, each equipped with ESI or MALDI sources.

Device characterization was performed under a nitrogen atmosphere inside the glovebox system (Blove-box line, Glove Box Technology Limited, Huntingdon, UK), using a Keithley 2634B Source Meter (Keithley Instruments, Cleveland, OH, USA) connected to a needle-probe station. Transfer and output characteristics were measure $+d$ within a voltage regime from $-70 \mathrm{~V}$ to $0 \mathrm{~V}$. The mobilities of the charge carriers $\left(\mu_{\text {sat }}\right)$ were calculated from the transfer characteristics in the saturation regime. To calculate mobility, a straight line was fitted to the linear region of the square root of the drain current in the saturation regime $\left(\mathrm{I}_{\mathrm{DS}}\right)^{1 / 2}$ (Figure 2a). 
a)

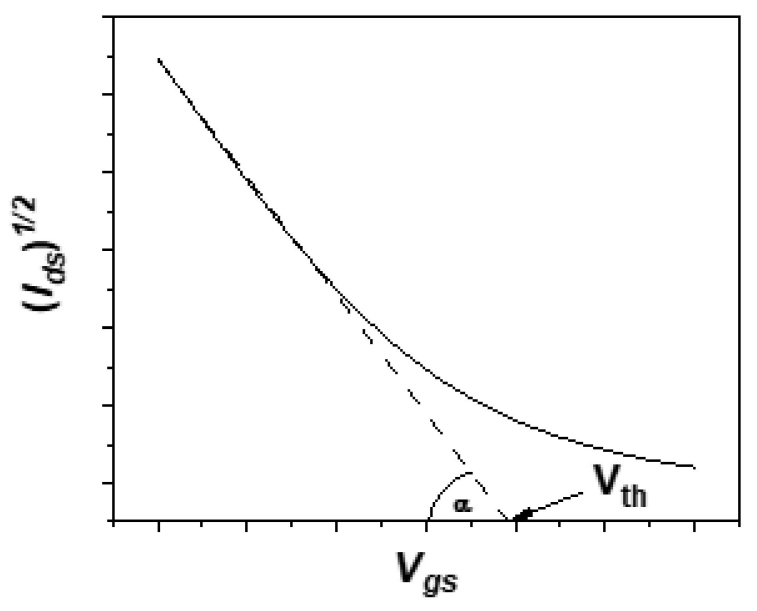

b)

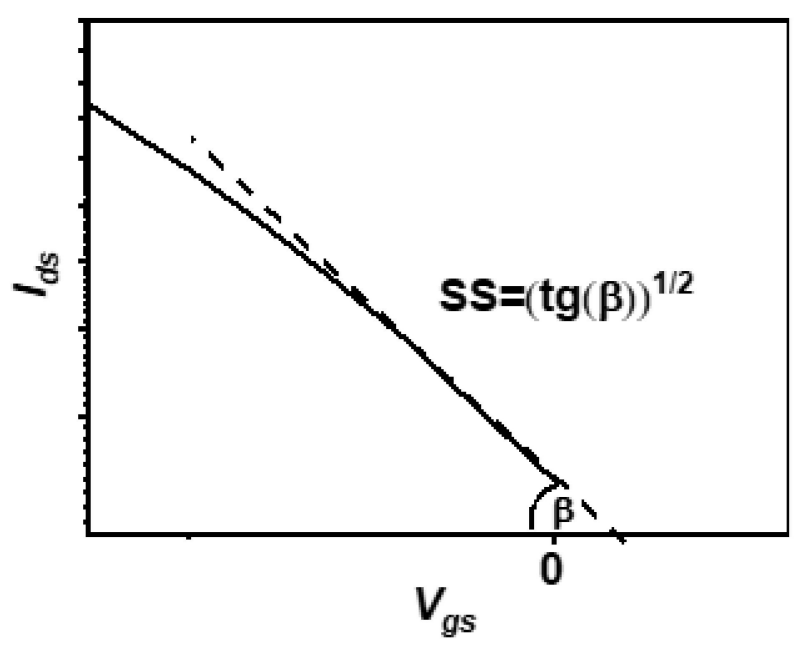

Figure 2. OFET transfer characteristics with a straight line intersecting the $V_{g s}$ axis at $V_{t h}$ at the $\alpha$ angle fitted to the linear region of the curve (a); the subthreshold regime for the transfer characteristic with the line fitted to the transfer curve in half logarithmic scale (b).

Charge carrier mobility was derived using the formula:

$$
\mu_{\text {sat }}=\frac{2 \alpha^{2} L}{W C_{p}}
$$

where $W$ is the channel width, $L$ is the channel length, $C_{p}$ is the capacitance per area unit of the gate dielectric $\left(1.1 \times 10^{-4} \mathrm{~F} \mathrm{~m}^{-2}\right)$, and $\alpha$ is the slope of the fitted straight line. The charge carrier mobilities presented here are the average values obtained for 4-5 devices. The threshold voltage was estimated as the cross point of the fitted line and $V_{g s}$ axis. The subthreshold swing $(S S)$ of the measured OFETs was determined as the reciprocal value of the slope of the fitting line to the subthreshold regime in the transfer curves of the OFETs (Figure 2b, Equation (2)).

$$
S S=\frac{d V}{d\left(\log \left(I_{D S}\right)\right)} \text { for } V_{G S}<V_{t h}
$$

The density of trap states at the interface $\left(N_{i t}\right)$ was calculated using the equation [35]:

$$
N_{i t}=\frac{C_{p}}{q^{2}}\left(\frac{q S S}{k T(\ln 10)}-1\right) \text {, }
$$

where $q$ is the elementary charge and $T$ is the temperature.

The ON/OFF ratio was calculated by dividing the Ids current for the highest $V_{d s}$ and $V_{g s}$ voltages by the $I_{d s}$ current for at the same $V_{d s}$ and $V_{g s}=0 \mathrm{~V}$.

Electrostatic field homogeneity was tested using a scanning probe microscope (SPM) working in the electrostatic force microscope regime. Electrostatic field maps were obtained using a Nanosurf Flex atomic force microscope (AFM, Nanosurf GmbH, Langen, Germany) combined with a C3000 controller. The conductive tip and gate electrodes were polarized using a Keithley SourceMeter Unit 2612b (Keithley Instruments, Cleveland, OH, USA). The applied voltage was chosen experimentally and was established as $2 \mathrm{~V}$ (on the tip) and $10 \mathrm{~V}$ (on the gate). In this dynamic non-contact mode, the tip, while moving over the gate dielectric, is sensitive to the electrostatic field formed over the gate. Topography images were obtained using the atomic force microscope mode of the SPM. The data were processed using Gwyddion software (Version 2.58, Czech Metrology Institute, Brno, 
Czech Republic) [36]. Scanning electron microscopy (SEM) was performed using a Jeol JSM-7900F (JEOL Ltd., Akishima, Japan).

\section{Results and Discussion}

A series of $N$-substituted zwitterionic BQMIs compounds (1-4) was synthesized by straightforward transamination of commercially available 4,6-diaminoresorcinol dihydrochloride in the presence of an excess of amine (Scheme 1) [32]. The reaction proceeded faster in the presence of alkylamines (compounds 1-2), whereas transamination using aniline derivatives required heating for several days to obtain compounds 3-4 [33,34]. The new lipophilic zwitterions 1-2 were isolated with yields of $60-73 \%$ after aqueous extraction followed by precipitation in pentane. They were characterized by ${ }^{1} \mathrm{H},{ }^{13} \mathrm{C}$ NMR and HRMS (see Materials Section and Supplementary Materials). To evaluate the hydrophobic character of the $\mathrm{BQMI}$-modified $\mathrm{SiO}_{2}$ dielectric surfaces, the contact angle was measured. Figure 3 presents pictures of a droplet of pure deionized water placed on the bare dielectric (Figure 3a) and an oxide surface modified with compound 3 (Figure 3b). The contact angle for the bare oxide was around $20^{\circ}$, whereas on the modified surface it increased to $84^{\circ}$. This variation in the contact angle means that the surface coated with BQMI 3 was much more hydrophobic than bare silicon dioxide. Similar behavior was observed for all the tested BQMI compounds. The differences in contact angles between the compounds were in the range of $+/-5$ degrees. Small differences may arise due to the optical method of determining CA. The hydrophobicity of the BQMI thin layer was stable in air. One week after deposition the contact angle was similar, at $82^{\circ}$. In general, BQMI zwitterions can be stored as powders under air conditions for months (even years) without undergoing any decomposition.

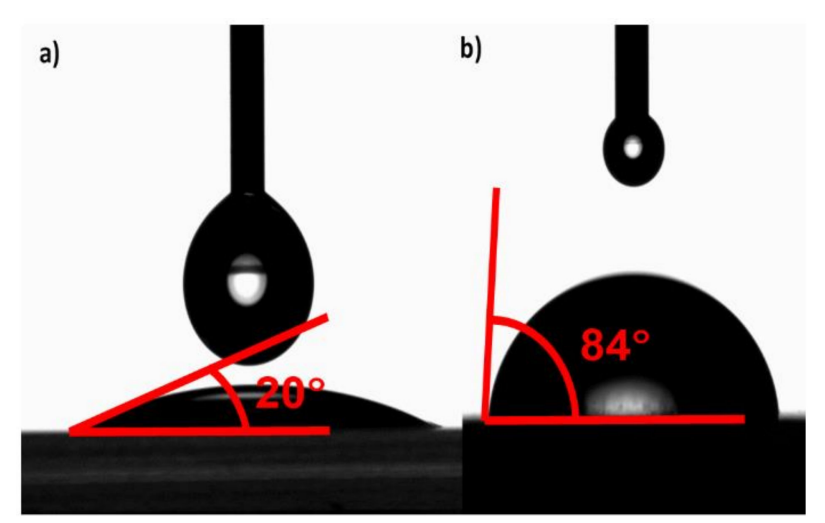

Figure 3. Droplet of water placed on the gate dielectric without a BQMI layer (a) and on a dielectric surface coated with BQMI compound 3 (b).

The spin-coated BQMIs deposited directly on the $\mathrm{SiO}_{2}$ dielectric surface created thin interlayers. Scanning electron microscopy (SEM) was used to examine the cross-sections obtained for the zwitterion 3-based layer deposited on a pure silicon substrate. However, the SEM pictures showed no visible BQMI layers, suggesting that their thickness was lower than $10 \mathrm{~nm}$ (see Supplementary Data). To analyze the quality of the BQMI-based interlayers, their topography was studied using AFM. Figure $4 \mathrm{a}, \mathrm{b}$ present the topographies of the pure and coated dielectric surfaces. As can be seen, there were no significant differences in the topography of the layers. Electrostatic maps obtained for the uncoated dielectric surface and the dielectric surface coated with BQMI 2 are presented in Figure $4 \mathrm{c}, \mathrm{d}$, respectively. The electrostatic field over the non-coated surface exhibits sites (black dots) where the SPM cantilever was approached to the surface while scanning. This indicates a weak electrostatic field, caused by additional negative charges trapped under the surface (in the boron doped silicone gate electrode, as well as in the silicon oxide dielectric layer). The extra electrons may have come from the inhomogeneities created during silicon doping. After coating of the dielectric surface with BQMIs, the molecules create a uniform layer. Their shielding 
properties cause the presence of charge carrier traps that are not reflected in the electrostatic field. The electric field is homogeneous, and the absence of local distortion does not affect the charge carrier mobility in the OFETs. The other BQMI AFM images resemble those presented in Figure 4 (see Supplementary Materials).
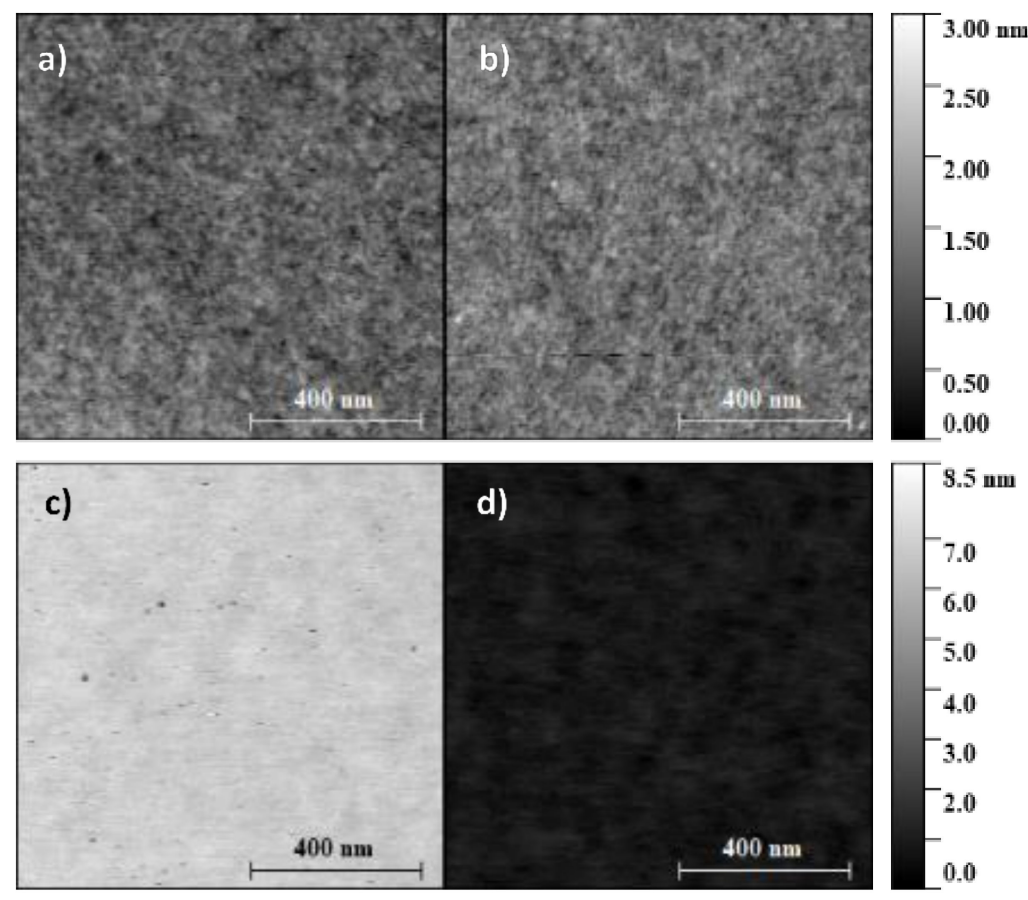

Figure 4. Atomic force microscope topography $(\mathbf{a}, \mathbf{b})$ and electrostatic force microscope images $(\mathbf{c}, \mathbf{d})$ of gate dielectrics without a BQMI layer (left side) and coated with BQMI 2 (right site).

To estimate the influence of the other derivatives of zwitterionic interlayers on the performance of the OFETs, a series of BQMI-based devices was fabricated with four different compounds (1-4). The morphology of the BQMI layers was examined by means of AFM. The roughness of the layers did not exceed $2 \mathrm{~nm}$, and their surface topographies were similar. Transistors without an interlayer and with an HDMS interlayer were elaborated as references, as the mechanism of HDMS operation is similar to the mechanism of zwitterion operation, being mainly based on a reduction in the number of trapping sites. The measured output current voltage characteristics of the OFETs are presented in Figure 5. The transfer curves are presented in Figure 6.

All measured characteristics were consistent with previously reported data for $\mathrm{p}$ type OFETs [37]. In the samples with a BQMI interlayer, the value of the OFF current reduced from $1.6 \times 10^{-7} \mathrm{~A}$ for the bare sample to $6.2 \times 10^{-8} \mathrm{~A}$ for BQMI compound 1, to $8.7 \times 10^{-8}$ A for BQMI compound 2, to $2.9 \times 10^{-8}$ A for BQMI compound 3 , and to $5.6 \times 10^{-9}$ for BQMI compound 4 .

By comparison, the OFF current of the sample with an HMDS interlayer was $8 \times 10^{-8} \mathrm{~A}$. Figure 7 compares the relevant OFETs parameters of selected field effect transistors, including charge carrier mobility, ON current, and the ON/OFF ratio. 

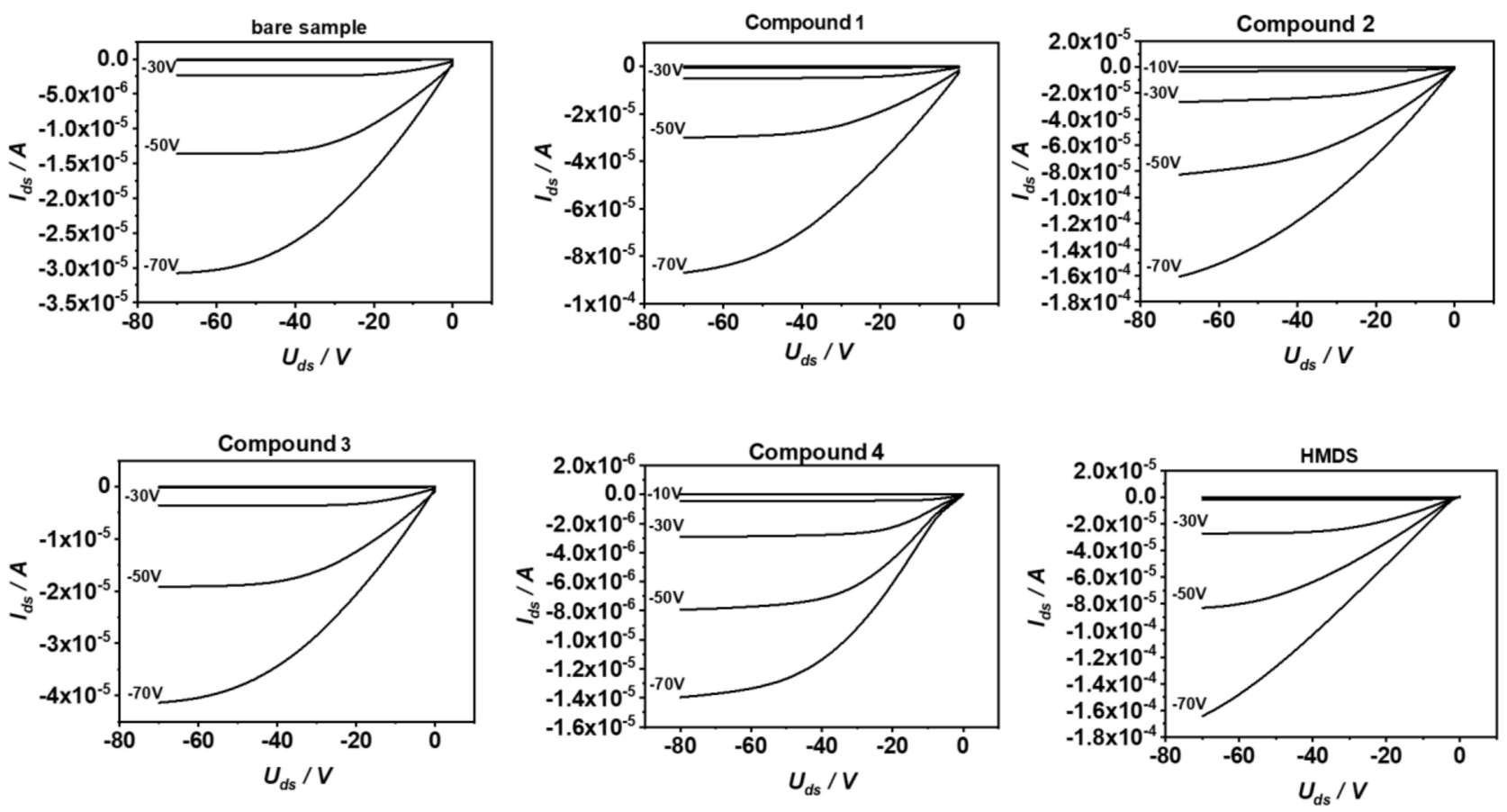

Figure 5. Output characteristics for transistors without a zwitterionic interlayer, with interlayers of BQMIs 1-4, and with an HMDS interlayer.
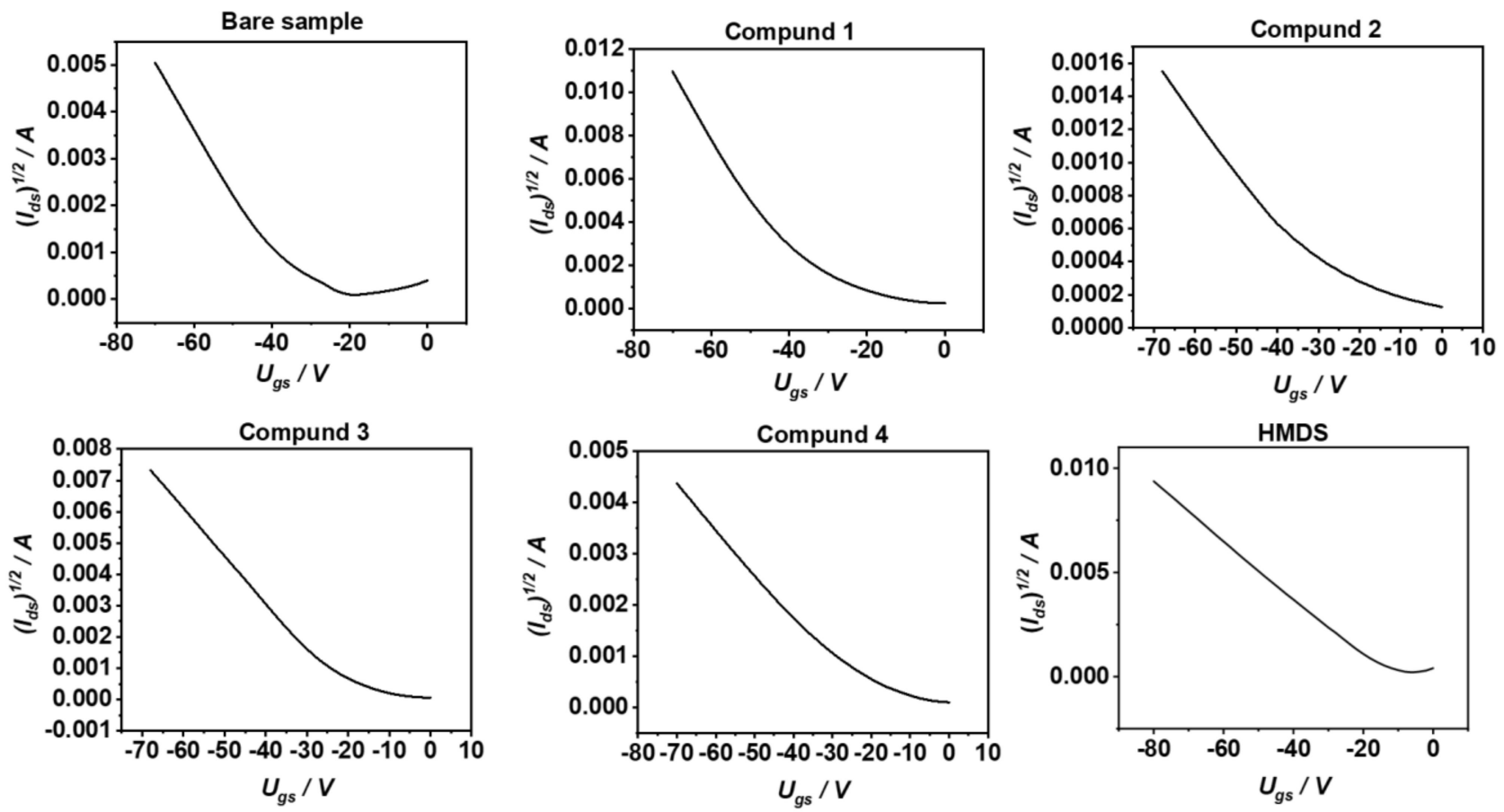

Figure 6. Transfer characteristics for transistors without a zwitterionic interlayer, with interlayers of BQMIs 1-4, and with an HMDS interlayer. 
a)

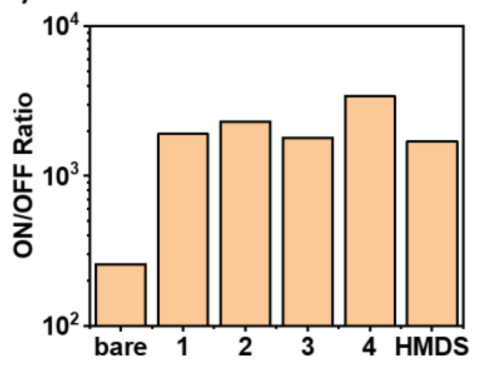

d)

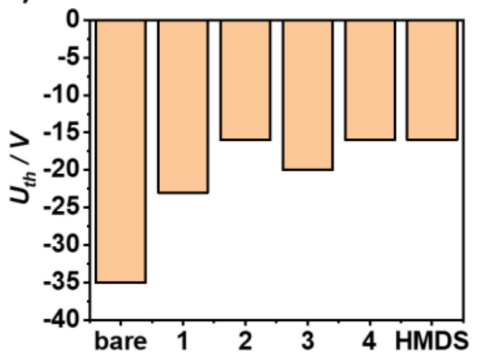

b)

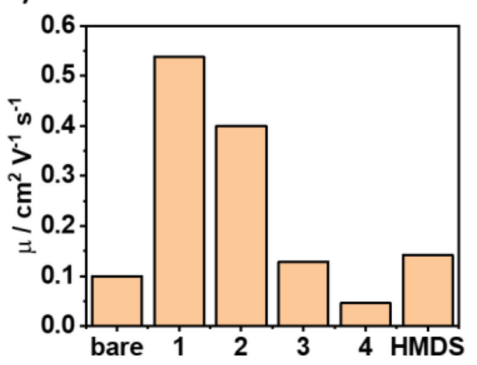

e)

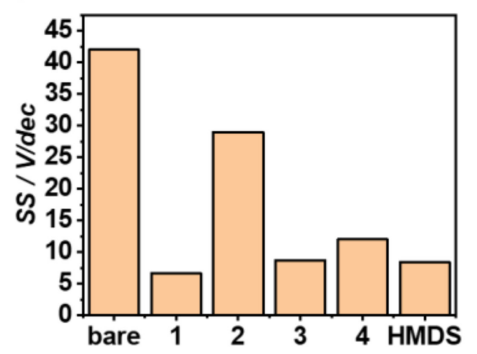

c)

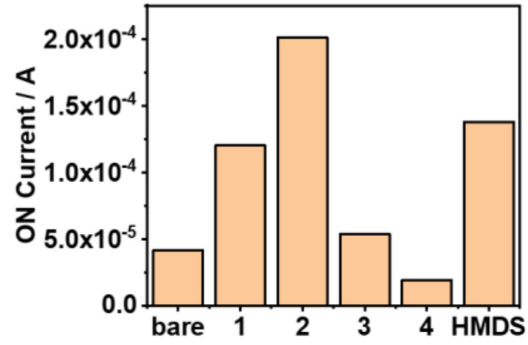

f)

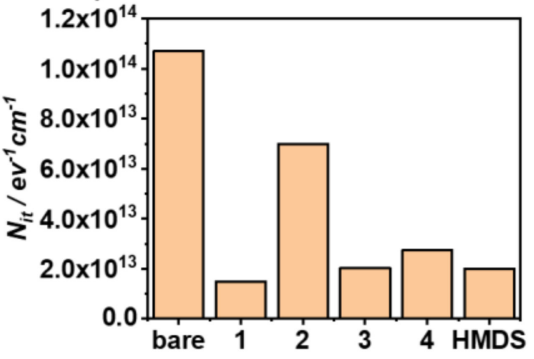

Figure 7. Bar charts comparing the ON/OFF ratio (a), charge carrier mobility (b), ON current (c), threshold voltage (d), subthreshold swing (e), and density of the interface traps (f) determined for selected OFETs with bare oxide BQMI compounds 1-4 or HMDS dielectric surface modification.

Charge carrier mobility was higher in the devices coated with BQMI compounds 1-3 compared to the bare sample. The introduction of the interlayer based on compound 4 resulted in poor charge carrier mobility, which may be explained by the relatively low solubility of this compound in organic solvents, including DMF solution. This necessitated the lowering of the concentration of DMF solution, which resulted in the creation of discontinuous films. Importantly, the charge carrier mobility values calculated for the transistors containing interlayers based on zwitterions $\mathbf{1}$ and $\mathbf{2}$ were higher (respectively: $5.4 \times 10^{-1}$ and $4.0 \times 10^{-1} \mathrm{~cm}^{2} \mathrm{~V}^{-1} \mathrm{~s}^{-1}$ ) than the mobility values calculated for the sample with an HMDS interlayer $\left(1.3 \times 10^{-1} \mathrm{~cm}^{2} \mathrm{~V}^{-1} \mathrm{~s}^{-1}\right)$. BQMI derivatives 1 and 2 both have relatively long aliphatic side groups, and their flexibility may influence the packing density of the molecules on the dielectric surface, improving the smoothness of the interlayers. Bao and co-workers reported higher charge carrier mobility in devices with silane-coated dielectric layers with dense and crystalline OTS surface-modified layers than with disordered OTS [38]. The presence of such densely packaged interlayers may reduce the charge carrier trapping effect at the dielectric-semiconductor interface.

To verify whether this was the case, the density of the $\mathrm{N}_{\text {it }}$ traps was calculated using Equation (3) and SS taken from the OFET transfer characteristics (Figure 8). For OFETs with the bare oxide, the $\mathrm{N}_{\mathrm{it}}$ value was around $10^{14} \mathrm{eV}^{-1} \mathrm{~cm}^{-2}$, and for the transistors with a dielectric surface modified by BQMIs or HMDS the $N_{\text {it }}$ was nearly $2 \times 10^{13} \mathrm{eV}^{-1} \mathrm{~cm}^{-2}$. 


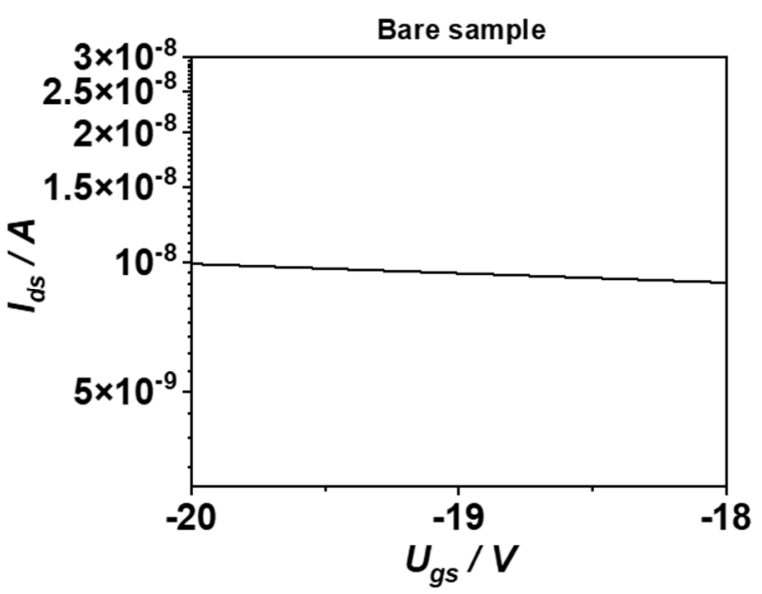

(a)

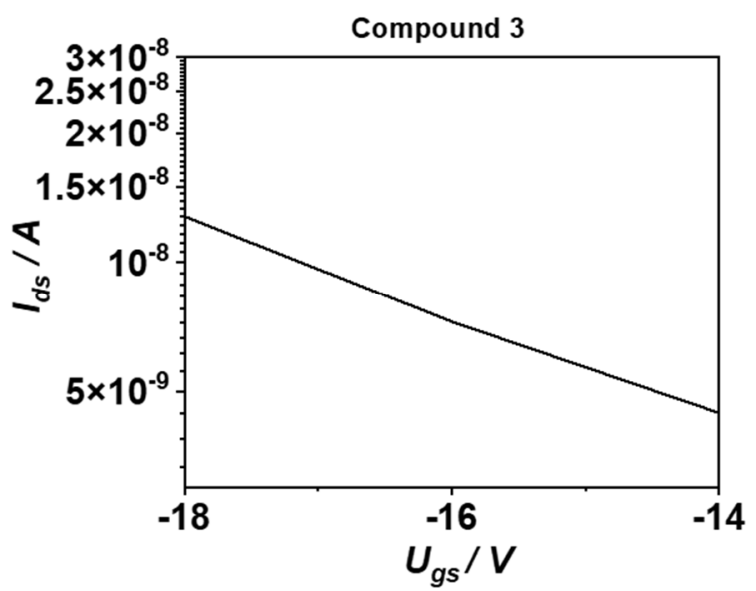

(b)

Figure 8. Subthreshold regime of transfer curves for transistors on silicon dioxide without a BQMI layer (a) and coated with compound $3(\mathbf{b})$.

In the case of transistors with a modified $\mathrm{SiO}_{2}$ surface, the reduction in the density of the traps contributed to an increase in the drain current flow.

\section{Conclusions}

Charge carriers are accumulated and transported in the dielectric-OSC interface. Therefore, its quality is crucial for OFET performance. A proper understanding and description of the interface is crucial to improving the efficiency of OFETs. The experimental work reported in this study demonstrates a new and easier method of modifying the silicon oxide layer, which allows for improvements in several parameters compared to transistors without modified dielectric surfaces. Our method is both less costly and less time-consuming than other commonly used modification techniques, such as coating dielectric layers on HMDS.

The zwitterions with aromatic side groups (3-4) were characterized by weaker solubility in DMF in comparison to their aliphatic analogues. Their incorporation into the OFET structure as interlayers did not lead to improved charge carrier mobility or increase the current flowing through the transistor channel. In contrast, the coating of bare $\mathrm{SiO}_{2}$ with $\mathrm{N}$-alkyl zwitterionic quinones caused changes to the water contact angle, as observed for compound 3 . The modified surface was characterized by a contact angle value of around $84^{\circ}$, compared to $20^{\circ}$ before modification. This presumably resulted in better ordering of the DPPDTT molecules in the semiconductor layer and improved the features of the OFET. The charge carrier mobility increased from $0.1 \mathrm{~cm}^{2} \mathrm{~V}^{-1} \mathrm{~s}^{-1}$ for the bare sample to $0.55 \mathrm{~cm}^{2} \mathrm{~V}^{-1} \mathrm{~s}^{-1}$ for the sample with the incorporation of zwitterion $\mathbf{1}$ as an interlayer.

A similar effect was observed for zwitterion 2. Both compounds are equipped with aliphatic side groups, allowing for higher packing density on the dielectric surface and improvement of the smoothness of the interlayers. Nevertheless, the transistors with zwitterion 2 were characterized by a relatively high value for SS, showing that the growth dynamic of the current in the subthreshold regime was low. This might be connected with the relatively high density of the traps at the semiconductor-dielectric interface. The shape of the output curves was a closer fit to the model transistor [39] in the case of the samples modified by BQMIs as compared to the HMDS-treated sample. The saturation region of the IV output characteristic began at a lower drain voltage, and its linear regime was shorter. The modification of the $\mathrm{SiO}_{2}$ surface with zwitterion 1 resulted in a decrease in the density of the surface charge carrier traps, by about one order of magnitude. This was related to the absence of disturbances in the electrostatic field near the modified surface, as confirmed by electrostatic force microscopy. This work opens new perspectives for the use of BQMI 
zwitterions in organic electronics, enabling highly versatile synthesis and fine-tuning of properties depending on the target applications.

Supplementary Materials: The following are available online at https:/ /www.mdpi.com/article/10 $.3390 /$ polym13101567/s1. Figure S1: ${ }^{1} \mathrm{H}$ NMR $\left(400 \mathrm{MHz}, \mathrm{CDCl}_{3}\right)$ of compound 1. Figure S2: ${ }^{13} \mathrm{C}$ NMR (100 MHz, $\left.\mathrm{CDCl}_{3}\right)$ of compound 1. Figure S3: 1H NMR (400 MHz, CDCl3) of compound 2. Figure S4: ${ }^{13} \mathrm{C} \mathrm{NMR}\left(100 \mathrm{MHz}, \mathrm{CDCl}_{3}\right)$ of compound 2. Figure S5: Infrared spectrum of compound 1. Figure S6: Infrared spectrum of compound 2. Figure S7: HRMS spectrum of compound 1. Figure S8: HRMS spectrum of compound 2. Figure S9: SEM picture of the cross-section of the BQMI 3 spincoated layer on a silicon wafer. Figure S10: AFM picture of the BQMI 1 spin-coated layer on a silicon wafer. Figure S11: AFM picture of the BQMI 3 spin-coated layer on a silicon wafer. Figure S12: AFM picture of the BQMI 4 spin-coated layer on a silicon wafer.

Author Contributions: Conceptualization, B.L. and O.S.; methodology, A.L., B.L., O.S., A.T.R.; validation, B.L., O.S.; formal analysis, A.L.; investigation, A.L., A.T.R., S.P., A.A.; data curation, A.L.; writing—original draft preparation, A.L.; writing—review and editing, B.L, O.S., S.P., J.J.; supervision, B.L., O.S.; project administration, B.L.; funding acquisition, B.L. All authors have read and agreed to the published version of the manuscript.

Funding: This work was supported by the Centre National de la Recherche Scientifique, the Ministère de la Recherche et des Nouvelles Technologies (France). O.S. thanks the Région SUD for the attribution of a PhD grant to A.T.R., and the ministère de l'Europe et des Affaires étrangères and NAWA for the PHC Polonium Program Exchange.

Institutional Review Board Statement: Not applicable.

Informed Consent Statement: Not applicable.

Data Availability Statement: The data presented in this study are available on request from the corresponding authors.

Acknowledgments: We thank Damien Chaudanson (CINaM) for carrying out SEM experiments.

Conflicts of Interest: The authors declare that they have no known competing financial interest or personal relationships that could have appeared to influence the work reported in this paper.

\section{References}

1. Benson, N.; Schidleja, M.; Melzer, C.; Schmechel, R.; von Seggern, H. Complementary organic field effect transistors by ultraviolet dielectric interface modification. Appl. Phys. Lett. 2006, 89, 182105. [CrossRef]

2. Don Park, Y.; Lim, J.A.; Lee, H.S.; Cho, K. Interface engineering in organic transistors. Mater. Today 2007, 10, 46-54. [CrossRef]

3. Sun, X.; Di, C.; Liu, Y. Engineering of the dielectric-semiconductor interface in organic field-effect transistors. J. Mater. Chem. 2010, 20, 2599-2611. [CrossRef]

4. Son, S.Y.; Kim, J.-H.; Song, E.; Choi, K.; Lee, J.; Cho, K.; Kim, T.-S.; Park, T. Exploiting $\pi-\pi$ Stacking for Stretchable Semiconducting Polymers. Macromolecules 2018, 51, 2572-2579. [CrossRef]

5. Naibi Lakshminarayana, A.; Ong, A.; Chi, C. Modification of acenes for n-channel OFET materials. J. Mater. Chem. C 2018, 6, 3551-3563. [CrossRef]

6. Chiarella, F.; Barra, M.; Ricciotti, L.; Aloisio, A.; Cassinese, A. Morphology, Electrical Performance and Potentiometry of PDIF-CN2 Thin-Film Transistors on HMDS-Treated and Bare Silicon Dioxide. Electronics 2014, 3, 76-86. [CrossRef]

7. Lim, S.C.; Kim, S.H.; Lee, J.H.; Kim, M.K.; Kim, D.J.; Zyung, T. Surface-treatment effects on organic thin-film transistors. Synth. Met. 2005, 148, 75-79. [CrossRef]

8. Di, C.; Liu, Y.; Yu, G.; Zhu, D. Interface Engineering: An Effective Approach toward High-Performance Organic Field-Effect Transistors. Acc. Chem. Res. 2009, 42, 1573-1583. [CrossRef]

9. Chen, F.-C.; Liao, C.-H. Improved air stability of n-channel organic thin-film transistors with surface modification on gate dielectrics. Appl. Phys. Lett. 2008, 93, 103310. [CrossRef]

10. Celle, C.; Suspène, C.; Ternisien, M.; Lenfant, S.; Guérin, D.; Smaali, K.; Lmimouni, K.; Simonato, J.P.; Vuillaume, D. Interface dipole: Effects on threshold voltage and mobility for both amorphous and poly-crystalline organic field effect transistors. Org. Electron. 2014, 15, 729-737. [CrossRef]

11. Egginger, M.; Bauer, S.; Schwödiauer, R.; Neugebauer, H.; Sariciftci, N.S. Current versus gate voltage hysteresis in organic field effect transistors. Mon. Chem.-Chem. Mon. 2009, 140, 735-750. [CrossRef]

12. Veres, J.; Ogier, S.; Lloyd, G.; de Leeuw, D. Gate Insulators in Organic Field-Effect Transistors. Chem. Mater. 2004, 16, 4543-4555. [CrossRef] 
13. Janasz, L.; Luczak, A.; Marszalek, T.; Dupont, B.G.R.; Jung, J.; Ulanski, J.; Pisula, W. Balanced Ambipolar Organic Field-Effect Transistors by Polymer Preaggregation. ACS Appl. Mater. Interfaces 2017, 9. [CrossRef] [PubMed]

14. Patil, B.B.; Takeda, Y.; Singh, S.; Wang, T.; Singh, A.; Do, T.T.; Singh, S.P.; Tokito, S.; Pandey, A.K.; Sonar, P. Electrode and dielectric layer interface device engineering study using furan flanked diketopyrrolopyrrole-dithienothiophene polymer based organic transistors. Sci. Rep. 2020, 10, 19989. [CrossRef]

15. Ruscello, M.; Stolz, S.; Gonzalez Arellano, D.L.; Ullrich, F.; Hillebrandt, S.; Mankel, E.; Pucci, A.; Kowalsky, W.; Emrick, T.; Briseno, A.L.; et al. Electron injection and interfacial trap passivation in solution-processed organic light-emitting diodes using a polymer zwitterion interlayer. Org. Electron. 2017, 50, 384-388. [CrossRef]

16. Wang, H.; Song, J.; Qu, J.; Lian, J.; Qian, P.-C.; Wong, W.-Y. A novel perylene diimide-based zwitterion as the cathode interlayer for high-performance perovskite solar cells. J. Mater. Chem. A 2020, 8, 18117-18124. [CrossRef]

17. Chen, L.; Yin, Z.; Mei, S.; Xiao, X.; Wang, H.-Q. Enhanced photoelectric performance of inverted CsPbI2Br perovskite solar cells with zwitterion modified ZnO cathode interlayer. J. Power Sources 2021, 499, 229909. [CrossRef]

18. Akin, S. Boosting the efficiency and stability of perovskite solar cells through facile molecular engineering approaches. Sol. Energy 2020, 199, 136-142. [CrossRef]

19. Liu, Y.; Sheri, M.; Cole, M.D.; Emrick, T.; Russell, T.P. Combining Fullerenes and Zwitterions in Non-Conjugated Polymer Interlayers to Raise Solar Cell Efficiency. Angew. Chem. Int. Ed. 2018, 57, 9675-9678. [CrossRef]

20. Xiao, J.; Zhang, Z.; Wu, D.; Routaboul, L.; Braunstein, P.; Doudin, B.; Losovyj, Y.B.; Kizilkaya, O.; Rosa, L.G.; Borca, C.N.; et al. The interface bonding and orientation of a quinonoid zwitterion. Phys. Chem. Chem. Phys. 2010, 12, 10329-10340. [CrossRef]

21. Routaboul, L.; Braunstein, P.; Xiao, J.; Zhang, Z.; Dowben, P.A.; Dalmas, G.; Da Costa, V.; Félix, O.; Decher, G.; Rosa, L.G.; et al. Altering the Static Dipole on Surfaces through Chemistry: Molecular Films of Zwitterionic Quinonoids. J. Am. Chem. Soc. 2012, 134, 8494-8506. [CrossRef]

22. Simpson, S.; Kunkel, D.A.; Hooper, J.; Nitz, J.; Dowben, P.A.; Routaboul, L.; Braunstein, P.; Doudin, B.; Enders, A.; Zurek, E. Coverage-Dependent Interactions at the Organics-Metal Interface: Quinonoid Zwitterions on Au(111). J. Phys. Chem. C 2013, 117, 16406-16415. [CrossRef]

23. Simpson, S.; Hooper, J.; Miller, D.P.; Kunkel, D.A.; Enders, A.; Zurek, E. Modulating Bond Lengths via Backdonation: A FirstPrinciples Investigation of a Quinonoid Zwitterion Adsorbed to Coinage Metal Surfaces. J. Phys. Chem. C 2016, 120, 6633-6641. [CrossRef]

24. Routaboul, L.; Tanabe, I.; Santana, J.C.; Yuan, M.; Ghisolfi, A.; Garcia, W.S.; Dowben, P.A.; Doudin, B.; Braunstein, P. Changes in molecular film metallicity with minor modifications of the constitutive quinonoid zwitterions. RSC Adv. 2017, 7, 21906-21917. [CrossRef]

25. Kunkel, D.A.; Simpson, S.; Nitz, J.; Rojas, G.A.; Zurek, E.; Routaboul, L.; Doudin, B.; Braunstein, P.; Dowben, P.A.; Enders, A. Dipole driven bonding schemes of quinonoid zwitterions on surfaces. Chem. Commun. 2012, 48, 7143-7145. [CrossRef]

26. Koudia, M.; Nardi, E.; Siri, O.; Abel, M. On-surface synthesis of covalent coordination polymers on micrometer scale. Nano Res. 2017, 10, 933-940. [CrossRef]

27. Denawi, H.; Koudia, M.; Hayn, R.; Siri, O.; Abel, M. On-Surface Synthesis of Spin Crossover Polymeric Chains. J. Phys. Chem. C 2018, 122, 15033-15040. [CrossRef]

28. Fang, Y.; Nguyen, P.; Ivasenko, O.; Aviles, M.P.; Kebede, E.; Askari, M.S.; Ottenwaelder, X.; Ziener, U.; Siri, O.; Cuccia, L.A. Charge-assisted hydrogen bond-directed self-assembly of an amphiphilic zwitterionic quinonemonoimine at the liquid-solid interface. Chem. Commun. 2011, 47, 11255-11257. [CrossRef]

29. Behyan, S.; Gritzalis, D.; Schmidt, R.; Kebede, E.; Cuccia, L.A.; DeWolf, C. Structural organization and phase behaviour of meta-substituted dioctadecylaminobenzoquinones at the air/water interface. Phys. Chem. Chem. Phys. 2019, 21, 2345-2350. [CrossRef]

30. Mahmood, A.; Yang, C.-S.; Jang, S.; Routaboul, L.; Chang, H.; Ghisolfi, A.; Braunstein, P.; Bernard, L.; Verduci, T.; Dayen, J.-F.; et al. Tuning graphene transistors through ad hoc electrostatics induced by a nanometer-thick molecular underlayer. Nanoscale 2019, 11, 19705-19712. [CrossRef] [PubMed]

31. Lin, Y.; Li, X.; Liu, X.; Liu, L.; Wang, W.; Wang, Z.; Liao, Y.; Tang, X.; Zheng, Y. Quinonoid Zwitterion: An Amphiphilic Cathode Interlayer with Initial Thickness-Insensitive and Self-Organizing Properties for Inverted Polymer Solar Cells. ACS Appl. Mater. Interfaces 2020, 12, 3792-3799. [CrossRef] [PubMed]

32. Yang, Q.-Z.; Siri, O.; Braunstein, P. First transamination reactions for the one-pot synthesis of substituted zwitterionic quinones. Chem. Commun. 2005, 21, 2660-2662. [CrossRef]

33. Tamboura, F.B.; Cazin, C.S.J.; Pattacini, R.; Braunstein, P. Reactions of Amines with Zwitterionic Quinoneimines: Synthesis of New Anionic and Zwitterionic Quinonoids. Eur. J. Org. Chem. 2009, 2009, 3340-3350. [CrossRef]

34. Ruiz, A.T.; Bousquet, M.H.E.; Pascal, S.; Canard, G.; Mazan, V.; Elhabiri, M.; Jacquemin, D.; Siri, O. Small Panchromatic and NIR Absorbers from Quinoid Zwitterions. Org. Lett. 2020, 22, 7997-8001. [CrossRef] [PubMed]

35. Glowacki, I.; Jaroslw, J.; Wiosna-Salyga, G.; Chapran, M.; Luczak, A.; Dupont, B.G.R.; Luszczynska, B.; Ulanski, J. Role of Charge-Carrier Trapping in Organic. Disp. Imaging 2017, 2, 279-319.

36. Nečas, D.; Klapetek, P. Gwyddion: An open-source software for SPM data analysis. Open Phys. 2012, 10, 181-188. [CrossRef] 
37. Afzal, T.; Iqbal, M.J.; Iqbal, M.Z.; Sajjad, A.; Raza, M.A.; Riaz, S.; Kamran, M.A.; Numan, A.; Naseem, S. Effect of postdeposition annealing temperature on the charge carrier mobility and morphology of DPPDTT based organic field effect transistors. Chem. Phys. Lett. 2020, 750, 137507. [CrossRef]

38. Virkar, A.; Mannsfeld, S.; Oh, J.H.; Toney, M.F.; Tan, Y.H.; Liu, G.; Scott, J.C.; Miller, R.; Bao, Z. The Role of OTS Density on Pentacene and C60 Nucleation, Thin Film Growth, and Transistor Performance. Adv. Funct. Mater. 2009, 19, 1962-1970. [CrossRef]

39. Köhler, A.; Bässler, H. Electronic Processes in Organic Semiconductors; Wiley-VCH Verlag GmbH \& Co. KGaA: Weinheim, Germany, 2015; ISBN 978-3-527-33292-2. 